\title{
Measuring Underground Economy of Bangladesh: Transaction Approach
}

\author{
A. F. M. Ataur Rahman ${ }^{1}$, Afsana Rahman Khan ${ }^{2}$ \\ ${ }^{1}$ Associate Professor, Department of Economics, North South University (NSU), Bangladesh \\ ${ }^{2}$ Department of Economics, North South University (NSU), Bangladesh
}

\begin{abstract}
Underground economy is a malaise for the government that restricts its fiscal ability and infuses confusion in development planning. For a developing country like Bangladesh, which thrives for prospering this can hurt disproportionately. Therefore, measuring underground economy is important for Bangladesh. In this study, using data of 1980-2010 we have used transaction method proposed by Feige (1979) to calculate its extent in Bangladesh. We have found that unreported economy accounts a substantial portion of official GDP. Its growth rate was high positive in some years and in some other years it experienced a stagnant trend. Although few but in some years it declined relative to GDP as well.
\end{abstract}

Key words: Underground Economy, Transaction Approach, Bangladesh

GEL Classification Code: A31; 040

\section{INTRODUCTION}

Underground economy is a well-accepted phenomenon in Macroeconomics. It is the part of economy that is not reported in public accounting and hence cannot be a part of decisions. Acknowledging existence of such sector is awkward for any government as it highlights its oblivion regarding its economy, nevertheless it exists in almost all countries. Bangladesh is not an exception. Few studies have empirically proven its existence for Bangladesh.

The existence of this underground economy was first recognized in early 1970's. There is no standard definition of underground economy and thus a plethora of terms like, informal, unofficial, irregular, unrecorded, hidden, shadow economy etc are available in literature. Strictly speaking, there are small differences among the concepts that these terms refer. Typically, underground economy refers to the portion of an economy that escapes official attention. It may contain large number of individually owned small production facilities and service providers using cheap, labor intensive technology. These activities may be too insignificant for a government to run after. Therefore, if they voluntarily keep themselves out of government detection chances are slim that government will find those. Underground economy also includes illegal activities like, drug dealing, prostitution, trading of stolen goods, bribery etc. There is no way that these activities can be revealed to the government. Some activities are avertedly kept secret from government because of tax purpose. In fact, such activities constitute the largest portion of underground economy. According to United Nations Economic and Social Council (2006) "the informal sector can be seen on streets, sidewalks and back alleys of cities and includes petty traders, street vendors, coolies and porters, small 
artisans, barbers and shoeshine boys". For our purpose, underground economy includes unreported incomes which may be derived from the production of legal and illegal goods and services.

Theoretically speaking, government should not be concerned about keeping track of every economic activity of its economy as long as activities are legal and do not encourage something that are malicious to the society. However, modern governments live on tax revenue and a major portion of tax is collected as income tax, which is directly related the level of economic activities. Therefore, keeping track of all income generating activities are necessary for the government for its own sake. Governments keep vigilance on their economy to detect possible tax evasion by introducing convoluted tax regulations and economic agents make their procedure more and more articulated to evade such surveillance. This is a dynamic cat and mouse game. An inevitable consequence of intricate, abstruse, esoteric tax system is disappearance of economic activities from official sector at a higher rate.

In this paper, we would like to investigate the existence and extent of underground economy for Bangladesh. There are few such previous studies dedicated only on Bangladesh and some cross-country analysis that include Bangladesh in their cross section. They all found existence of underground economy in Bangladesh. However, in some sense their data are relatively outdated. Contribution of this paper will be an updated measure of underground economy of Bangladesh following transaction method, which to the best of our knowledge was never applied on Bangladeshi data.

Rest of the paper is organized as follows: next section discusses relevant literature followed by the section of methodology and data discussion. Result obtained is presented in the subsequent section. Concluding remarks are in the concluding section.

\section{LITERATURE REVIEW}

- We can identify few causes that may induce people to participate in underground economy. The most significant and often cited causes are:

- In case of rise of tax and social security burden, underground can serve as a way out for marginal taxpayers. Sometimes, when tax rate per se is not high enough, service provided by the government may not meet expectations of taxpayers and they may feel discouraged to pay taxes properly.

- Sometimes tax regulations becomes so difficult and heavy for employers and employees so they deliberately settle down in underground economy where employees may get less but do not have to deal with troublesome regulations.

- Forced reduction of working hour, early retirement; unemployment, sometimes may induce people to work in unreported sector.

- Falling tax morale can always explain such acts. Sometimes acceptability of the government among its people can contribute to waning tax morale.

Apart from these "supply" side reasons, there may be some demand side reasons as well:

- Underground economy is normally more efficient than over the ground economy. Over the ground economy, generally requires to comply with many regulations, therefore can be quite bureaucratic. In that respect, underground economy is "direct" and dynamic.

- Underground economy may supply goods and services that are well demanded in market but are not supplied by existing system.

- In underground economy, market operates closer to free market principles than over the ground economy and thus can encourage entrepreneurship.

- Underground economy operates as a failure of official economy. Therefore, its operation is an answer of "illegal" rules, oppressions, social exclusion and things of that sort. 
Measuring underground economy is a challenge for economists and they devised a number of ways to address that challenge. These methodologies can be broadly classified in two groups: direct and indirect. In direct method researcher wants to estimate the extent of undeclared income through extensive representative survey (Williams, 2006) or tax auditing (Thomas, 1992). Although such procedures are conceptually fine and can give first hand knowledge about hidden income yet their accuracy is frequently questioned, as respondent may not be quite comfortable to answer questions involving their undisclosed income. Survey based methods have their innate limitations, like biasness.

Indirect methods try to determine the size of underground economy by picking intelligent traces or indicators that underground economy may leave behind. Underground activities are deliberately kept hidden from government's notice therefore; they are not in official statistics. However, if we run clever investigation to diagnose "inconsistencies" between different macro variables then we can trace underground economy. Examples of such indirect methods are physical input (electricity consumption) approach, monetary approach, transaction approach, structural equation approach etc. In physical input method, we try to find out discrepancy between expected output based on energy consumption and actual output. Their difference is considered to be hidden (see Feige and Urban, 2008).

Gutmann (1977) first introduced monetary approach and subsequently are followed in many studies. Gutmann (1977) in his groundbreaking work tried to estimate the size of underground economy of the United States for the year 1976. He made a crucial assumption that there was no underground economy prior to World War II. Such assumption has become increasingly popular since then. Most of the methods that measure underground economy make such assumption. Feige (1979) Tanzi(1980,1982, 1983), Klovland (1980, 1984), Bhattacharyya (1990), and Escobedo and Mauleon (1991) and many other studies developed different variants of the monetary approach and applied for estimation underground economy of countries like U.S., Italy, Norway, Canada, South Africa, Tanzania, Mexico, India, Australia, Austria, Belgium, Denmark, France, Germany, Great Britain, Ireland, Netherlands, New Zealand, Spain, Sweden, Switzerland Argentina, etc.

Ahumada, Alvaredo and Canavese (2008) identified popularity of monetary method because of motivational simplicity and intuitive nature. In fact, a sizable literature on underground economy is available and an interested reader can find an interesting survey in Schneider and Enste (2000), Kazemier (2006), Pickhardt and Shinnick (2008) or Adair (2011).

Researches have been done on Bangladeshi underground economy as well. Reza (1989) guesstimated size of black economy for Bangladesh of 1985 as one third of official economy. That study did not follow any particular methodology rather some informed discussion and local knowledge served as the base of such deliberation. Later Hassan, (1997) following currency model estimated underground economy of Bangladesh and found the figure as around 23 percent of the formal GDP during 1972 - 95. In a cross-country study Schneider, Buehn and Montenegro (2010) found the size of the underground economy in Bangladesh was 35.9\% of official GDP over 1999-2007. Buehn and Schneider (2011) also found similar figure for Bangladesh. Indicators (inequality, social insecurity, overcrowded cities, high rate of self employment, lower income tax and etc) that provide well established significance of the size of underground economy are deemed to be prevalent in Bangladesh and therefore we think that our study will also find presence of significant underground economy as well.

\section{Methodology}

As explained earlier, methodologies of determining underground economy has two broad categories, those are direct survey-based methods and indirect methods. Each class has its own 
strengths and limitations. However, the problem lies in the measurement technique. Government strive to detect unreported income but as soon as it succeeds it no longer remains in the underground. Transaction method is an indirect way to estimate underground activities from trails that it leaves behind in official economy.

As a part transaction method, we fixed year 1980, as our starting point of calculation. Rational behind such picking is that before 1980 the country was in severe political turmoil since its independence in 1971, which resulted fiscal indiscipline. During late 1970s political situation slowly improved and things started getting back on track. Therefore, it is a good time to start our calculation. This however does not mean that we are assuming prior to 1980 underground economy of Bangladesh non-existent. It just means that 1980 is good point to serve as baseline. We followed Feige (1979) methodology in our estimation. This methodology assumes that there is a constant relationship (denoted by $K$ ) between the money supply related to economic transactions and total value added (e.g. GDP). Feige's transaction method starts with Fisher's equation of exchange:

$M * V=P * T$

Where $M$ represents the money in circulation (sum of currency in circulation and demand deposits), $V$ is velocity of money (rate at which money circulated or turn over in an economy at a given time period), $P$ the price level and $T$ the level of transaction.

Following assumption of constant relationship between money flows related to transactions and total value added, therefore:

$P * T=K *\left(Y_{T}\right)$

Where $Y_{T}$ is the sum of official value added and underground value added. In other words, it is the sum of the total output of an economy considering both formal and informal segments. Hence,

$$
P * T=K *\left(Y_{O}+Y_{U}\right)
$$

Where $Y_{U}$ is the value added in underground sector and $Y_{O}$ is the value added in official sector. Bringing time dimension and substituting that in equation (1) we get:

$$
M_{t} * V_{t}=K *\left(Y_{O t}+Y_{U t}\right)
$$

Assuming zero underground economy at period $t=0$, we determine $K$ of that period and consider that $K$ to remain fixed throughout the whole period. We calculate the constant $K$ by simple algebraic manipulation of equation (3) above assuming $Y_{U t}$ equal to zero.

Armed with the benchmark value of $K$ we can calculate the value of $Y_{T}$ underground for subsequent periods, again using algebraic manipulation of equation (3) such that:

$$
Y_{U t}=\frac{M_{t} * V_{t}}{K}-Y_{O t}
$$

To determine the total money supply $(M)$ we summed up currency in circulation and demand deposits $(C C+D D=M)$. Then to get $M * V$, we multiplied money supply 
$(M)$ with velocity of money $(V)$. Following equation(3) our next step was to estimate the value of constant variable $(K)$, which we found as 0.53 .

Then using equation, (4) we calculated the value of underground economy.

\section{DATA}

Basic macroeconomic time series data on GDP, currency in circulation, demand deposits, velocity of money, and broad money (M2) are collected from Monthly Economic Indicators published by Bangladesh Bank and Statistical Yearbooks published by the Bangladesh Bureau of Statistics (BBS). Our focus was from fiscal year 1980 to fiscal year 2010.

We did not have data on velocity of money from fiscal year 1980 to fiscal year 1993; as a result, we had to calculate velocity. In order to calculate the velocity of money we used the Fischer equation:

$M * V=P^{*} T$

$M * V=Y$ as $P^{*} T=Y$

$V=\frac{Y}{M}$ in this case we used $M 2$, as money supply to avoid the problem of circularity in the equation]

We calculated velocity of money for some overlapping years just to ensure that our values are correct. As we found them matching we filled out missing figures and calculated underground economy.

\section{DESCRIPTION OF RESULTS}

Our result is given in the following table:

\begin{tabular}{|c|c|c|}
\hline Period & $\begin{array}{c}\text { Underground Economy } \\
\text { (Million BDT) }\end{array}$ & \% of Official GDP \\
\hline 1980 & 0.00 & 0 \\
\hline 1981 & $30,240.30$ & 0.093874 \\
\hline 1982 & $59,826.22$ & 0.165385 \\
\hline 1983 & $64,157.06$ & 0.157129 \\
\hline 1984 & $98,583.26$ & 0.201278 \\
\hline 1985 & $136,011.54$ & 0.242038 \\
\hline 1986 & $155,898.53$ & 0.246405 \\
\hline 1987 & $224,263.46$ & 0.308177 \\
\hline 1988 & $335,613.20$ & 0.419554 \\
\hline 1989 & $409,626.83$ & 0.459946 \\
\hline 1990 & $462,605.47$ & 0.461089 \\
\hline 1991 & $504,430.38$ & 0.456423 \\
\hline 1992 & $542,534.79$ & 0.453843 \\
\hline 1993 & $520,862.81$ & 0.415462 \\
\hline 1994 & $521,860.89$ & 0.385387 \\
\hline 1995 & $584,214.40$ & 0.383047 \\
\hline 1996 & $616,817.70$ & 0.370853 \\
\hline 1997 & $726,332.68$ & 0.401952 \\
\hline
\end{tabular}




\begin{tabular}{|l|c|c|}
\hline 1998 & $865,236.23$ & 0.432237 \\
\hline 1999 & $994,949.70$ & 0.452873 \\
\hline 2000 & $1,116,160.17$ & 0.470784 \\
\hline 2001 & $1,234,763.62$ & 0.486997 \\
\hline 2002 & $1,399,073.59$ & 0.512104 \\
\hline 2003 & $1,604,317.25$ & 0.53374 \\
\hline 2004 & $1,784,792.02$ & 0.536017 \\
\hline 2005 & $1,990,033.02$ & 0.536821 \\
\hline 2006 & $2,219,518.71$ & 0.533887 \\
\hline 2007 & $2,522,495.88$ & 0.533888 \\
\hline 2008 & $2,884,940.51$ & 0.528549 \\
\hline 2009 & $3,421,671.12$ & 0.556555 \\
\hline 2010 & $3,620,154.31$ & 0.521392 \\
\hline
\end{tabular}

The following graph shows the graphical version of this trend:

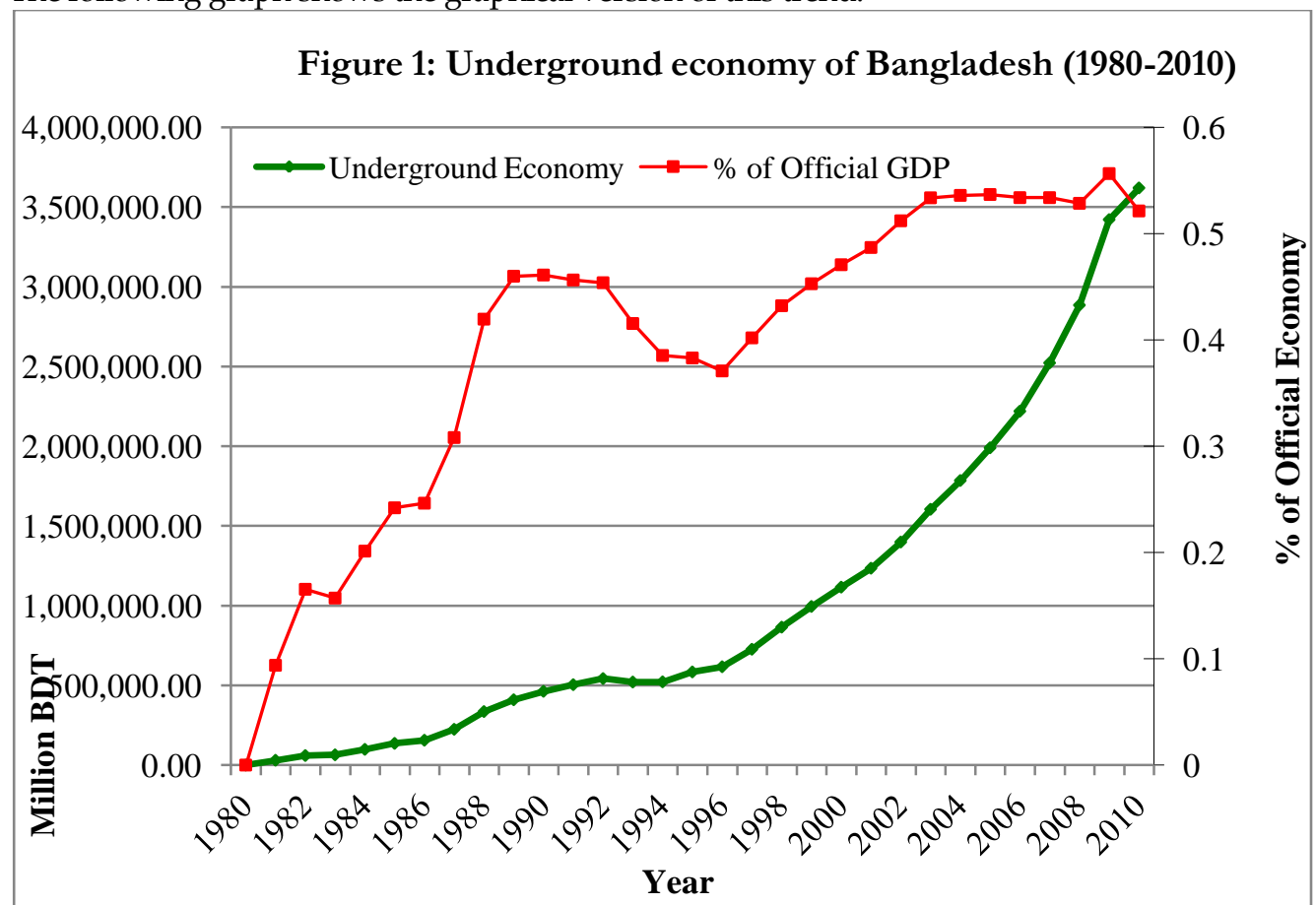

Since we arbitrarily selected our initial year therefore, calculated absolute figures will not be that informative. Growth figures will however, contain meaningful information. We can infer following conclusions from this exercise:

- Over this period (1980-2010) size of underground economy of Bangladesh was quite large

- Over these year underground economy increased almost steadily

- However, compared to official economy its growth pattern showed increasing trend in some years and decreasing trend in some other years

Underground economy is a macroeconomic phenomenon and therefore it is related with government policy. Following that vein, we can think of its relationship with political regimes 
of the country. During the period considered (1980-2010) there were quite a few regimes. It started with Ziaur Rahman, then Jatiya Party (Hussain Mohammed Ershad, 1982 to 1990), Bangladesh Nationalist Party (Khaleda Zia, 1991 to 1996), Awami League (Sheikh Hasina, 1996 to 2001), again by Bangladesh Nationalist Party (Khaleda Zia, 2002 to 2006), a caretaker government system (2006 to 2008) and finally again Awami League (Sheikh Hasina, 2009 to present).

During Ershard's tenure, underground economy grew more rapidly than the official economy. During this time unreported activities reached 45\% official economy assuming zero at 1980. This goes with the guesstimation of Reza (1989). In 1991, when Bangladesh Nationalist Party (BNP) came to power, the size of underground economy remained constant with respect to official economy. That is both sectors grew at a same pace. During the end of this tenure, it experienced even a mild decrease. After that, between 1996-2001 Awami League (AL) came to power and during this period, underground economy became almost double. We observe a steep rise (around 30\%) of this sector as percentage of GDP. When BNP again came to power underground economy again leveled off at around 50\% of the official GDP. Since then it has a small gain in last couple of years.

Regarding composition and causes of underground economy in Bangladesh, we can think of several avenues. Bangladesh has a large agricultural sector and a significant portion of the country's income comes from this sector. Earnings from this sector mostly remain out of government calculations. Hence, this income can give rise to the size of informal economy.

In urban economy, one of the booming sectors is real estate construction. Mostly day laborers work in these construction sites. As the level of construction grows with time; number and income of day laborers grow as well. They are mostly out of tax calculations. This could be another reason for the rapid increase in the size of informal economy.

In last two decades or so, Bangladesh has experienced fast and uneven growth. Urbanization is a dominant trend; people from the rural areas migrate to the capital city Dhaka in search of a better life and employment. Many of them engage themselves in small businesses such as, selling vegetables on the street, small tea shop at the corner of an alley etc. As the number of these people increase; unreported economy also become buoyant.

Finally, tax evasion can contribute significantly in this sector. Many people, in order to avoid tax do not register their businesses, and stay informal. In last decade or so, online home based businesses mushroomed in urban areas. Established businesses evade tax through false reporting and/or taking help of regulatory loopholes. Rise of professional class and their expansive lifestyle indicate their income level but they also are alleged to hide a significant portion of their legal and illegal income for tax purpose. Bangladesh in last decade has got significant criticism for being at the high end of the list of most corrupted countries around the world. Income from such corruption in the form bribery and undisclosed income, along with income from drug dealing contributes to the swelling figure of underground economy. Government officials of Bangladesh do not bear an immaculate image making tax evasion not the most difficult thing to do in Bangladesh. All these may contribute positively in the swelling of unreported sector.

\section{CONCLUSION}

Large underground economy can interfere with fiscal capacity of the government and thus may weaken government's possibility to tighten its grip on the economy. This is certainly not good for an economy like Bangladesh that thrives for growth and development. Although effect of underground economy on official economy is not clear in literature, it certainly 
interacts with growth potential and undermines government authority (Besley and Persson, 2010). Therefore, government of Bangladesh should at least keep an eye on growth of underground economy and if possible to restrict.

\section{BIBLIOGRAPHY}

Adair, P. (2011). Non-Observed Economy in the European Union countries (EU-15): A comparative analysis of estimates, in: M. Pickhardt and A. Prinz (eds.), Tax Evasion and The Shadow Economy, Cheltenham: Edward Elgar, forthcoming.

Ahumada, Hildegart, Facundo Alvaredo, and Alfredo Canavese, (2007), "The Monetary Method and the Size of the Shadow Economy: A Critical Assessment," Review of Income and Wealth, 53(2), 363-371.

Bhattacharyya, D. K. (1990). An econometric method of estimating the hidden economy, U.K. (1960-1984): estimates and tests, Economic Journal, 100, pp. 703-717.

Escobedo, M. I. and Mauleón, I. (1991). Demanda de dinero y economía sumergida, Hacienda Pública Española, 119, pp. 105-25.

Feige, E. and Urban, I. (2008) 'Measuring Underground (Unobserved, Non-Observed, Unrecorded) Economies in Transition Countries: Can We Trust GDP?', Journal of Comparative Economics 36: 287-306.

Feige, E., "How Big is the Irregular Economy? Challenge, 22(1), 5-13, 1979

Gutmann, P. (1977) 'The Subterranean Economy', Financial Analysts Journal 33: 26-34

Hassan K M (1997), The Estimation and Policy Implications of the Underground Economy: The Case for Bangladesh, The Bangladesh Development Studies, Vol. 25, No. 3/4 (Sept.- Dec. 1997), pp. 151-173

Kazemier, B. (2006). Monitoring the Underground Economy - A Survey of Methods and Estimates, in: Enste, D. and Schneider, F. (eds.), Jahrbuch Schattenwirtschaft 2006/2007, Vienna: LIT, pp. 11-53.

Klovland, J. T. (1980). In search of the hidden economy: Tax evasion and the demand for currency in Norway and Sweden. Discussion Paper 18/80, Norwegian School of Economics and Business Administration, 1980.

Klovland, J. T. (1984). Tax Evasion and the Demand for Currency in Norway and Sweden. Is there a Hidden Relationship? Scandinavian Journal of Economics, 86 (4), pp. 423-439.

Pickhardt, M. and Shinnick, E. (2008). Governance and Illicit Activities: A Survey of Recent Issues and Developments, in: Pickhardt, M. and Shinnick, E. (eds.), The Shadow Economy, Corruption and Governance, Edward Elgar: Cheltenham, pp. 3-17.

Reza, S (1989) Black Economy In Bangladesh: Some Preliminary Observations, Savings and Development, Vol. 13, No. 1 (1989), pp. 23-43

Schneider, F. and Enste, D. (2000). Shadow Economies: Size, Causes, Consequences, Journal of Economic Literature, 38, pp. 77-114.

Schneider, Friedrich, Andreas Buehn, and Claudio E. Montenegro (2010), "Shadow Economies all over the World: New Estimates for 162 Countries from 1999 to 2007," World Bank Policy Research Paper 5356. 
Schneider, Friedrich, Andreas Buehn, and Claudio E. Montenegro (2011), "Shadow Economies all over the World: New Estimates for 162 Countries from 1999 to 2007," forthcoming in: Schneider, Friedrich (Ed.), Handbook on the Shadow Economy, Edward Elgar Publishing

Tanzi, V., "The Underground Economy in the United States: Annual Estimates, 1930-80," IMF Staff Papers, 30(2), 1983.

Tanzi, V., "Underground Economy and Tax Evasion in the United States: Estimates and Implications," in V.Tanzi (ed.), The Underground Economy in the United States and Abroad, Lexington Books, 1982.

Tanzi, Vito, The Underground Economy in the United States: Estimates and Implications, Banco Nazionale del Lavoro, Rome, December 1980.

Thomas, J.J. (1992), Informal Economic Activity, LSE Handbooks in Economics, London: Harvester Wheatsheaf.

United Nations Economic and Social Council, (2006). The Role of Informal Sector in Poverty Reduction ( $3^{\text {rd }}$ ed.). Bangkok: United Nations Economic and Social Council.

Williams, C. C. (2006), Entrepreneurship and the Underground Economy: The Missing Link, Edward Elgar, Aldershot. 